\title{
BENEFICIAMENTO DE SEMENTES DE CAFÉ E EFEITOS NA QUALIDADE FISIOLÓGICA $\left({ }^{1}\right)$
}

\author{
GERSON SILVA GIOMO ( $\left.{ }^{2}\right)$; JOÃO NAKAGAWA $\left({ }^{3}\right)$; PAULO BOLLER GALLO $\left({ }^{4}\right)$
}

\begin{abstract}
RESUMO
Considerando-se a escassez de informações sobre o beneficiamento mecanizado de sementes de café, realizouse este trabalho para estudar seus efeitos na qualidade fisiológica das sementes de café arábica. Um lote de sementes de 'Catuaí Amarelo IAC 62' foi submetido à ação de máquina de pré-limpeza, máquina de ventiladores e peneiras e mesa densimétrica, em diversas combinações, e as sementes foram avaliadas quanto à germinação e ao vigor (envelhecimento acelerado, emergência de plântulas, altura e massa de matéria seca de plântulas e mudas). $\mathrm{O}$ teor de água das sementes também foi determinado. Utilizou-se o delineamento estatístico de blocos ao acaso, com quatro repetições, e o teste de Tukey a 5\% para comparação de médias. Concluiu-se que: a) a qualidade fisiológica das sementes foi aprimorada à medida que o lote passou por equipamentos específicos no beneficiamento, culminando com a melhor qualidade na sequiência operacional em que o lote foi submetido à ação da máquina de ventiladores e peneiras e mesa densimétrica; b) a mesa densimétrica, associada à máquina de ventiladores e peneiras, foi o equipamento que proporcionou a melhor separação de materiais que interferem negativamente na qualidade fisiológica das sementes; c) as sementes maiores e/ou mais pesadas tiveram qualidade fisiológica superior, e as sementes mocas graúdas, qualidade fisiológica similar à das sementes chatas graúdas; d) o descarte das frações do lote constituídas por sementes pequenas ou de menor densidade possibilitou a obtenção de lotes homogêneos e com alta qualidade fisiológica, favorecendo a obtenção de mudas mais vigorosas.
\end{abstract}

Palavras-chave: Coffea arabica L., sementes, classificação, germinação e vigor.

\section{ABSTRACT \\ COFFEE SEED PROCESSING AND EFFECTS ON PHYSIOLOGICAL SEED QUALITY}

The objective of this research was to obtain more suitable information concerning coffee seed processing in the air-screen machines and gravity table, studying their effects on the physiological seed quality. One coffee seed lot of the Yellow Catuaí IAC 62 cultivar was processed in a precleaner machine, in an air-screen cleaner and in a gravity table, working in several sequences and combinations, according to technical recommendations for seed processing. The seeds were evaluated as to their physiological quality by the germination test, accelerated aging test, seedling emergence, height and weight of dry matter of seedlings and young plants. The seed moisture was determined at the beginning of the evaluations. The statistical design was randomized blocks with four replications. Mean comparisons were done by the Tukey test at $5 \%$ of probability. It was concluded that: a) physiological seed quality was improved by specific equipments in the several phases of processing, with the best seed quality, obtained with complete operational sequence, where the lot was submitted to the action of the air-screen cleaner and gravity table; b) the gravity table, associated with air-screen cleaner, was effective in removing debris from the seed lot, improving the physiological seed quality; c) larger or denser seeds had superior physiological performance than small sizeor lowdensity seeds, and the large pea berry seeds presented physiological quality similar to the large flat seeds; d) discart of smallest or lightest seeds to improved the physiological seed quality, resulting in homogeneous, and high quality seed lots, and more vigorous young plants.

Key words: Coffea arabica L., seeds, grading, germination, vigor.

$\left({ }^{1}\right)$ Parte da tese de doutorado do primeiro autor apresentada à Faculdade de Ciências Agronômicas (FCA), Universidade Estadual Paulista (UNESP), Botucatu (SP). Com bolsa de doutorado do CNPq. Recebido para publicação em 25 de setembro e 2007 e aceito em 13 de junho de 2008.

$\left({ }^{2}\right)$ Centro de Café Alcides Carvalho, Instituto Agronômico (IAC), Caixa Postal 28, 13001-970 Campinas (SP). E-mail: gsgiomo@iac.sp.gov.br $\left(^{*}\right)$ Autor correspondente.

$\left({ }^{3}\right)$ Departamento de Produção Vegetal, UNESP/FCA, Botucatu (SP).

(4) Pólo Regional de Desenvolvimento Tecnológico dos Agronegócios do Nordeste Paulista, Mococa (SP). 


\section{INTRODUÇÃO}

A qualidade das sementes é o somatório de atributos genéticos, físicos, fisiológicos e sanitários que afetam a capacidade de estabelecimento e desenvolvimento de uma determinada planta (DeLouche e POTTS, 1974), podendo variar entre e dentro dos lotes em virtude de diferenças qualitativas presentes nas sementes, sob a interferência de inúmeros fatores desde a sua formação na planta até o momento da semeadura. Para minimizar essas interferências na qualidade fisiológica e, ao mesmo tempo, homogeneizar os lotes, efetua-se o beneficiamento das sementes, o qual constitui uma etapa essencial para o aprimoramento da qualidade (VAUGHAN et al., 1976).

Segundo Pollock e Roos (1972), as sementes de um mesmo lote podem diferir individualmente em termos de viabilidade e vigor, ou seja, há entre si diferentes potenciais fisiológicos. Assim, a classificação das sementes, por tamanho e por massa específica, constitui prática rotineira no beneficiamento da maioria das espécies agrícolas, para a separação de sementes com baixo potencial fisiológico, conforme relatam VAUGHAN et al. (1976), os quais evidenciam que a eliminação de frações do lote constituídas por sementes de menor tamanho e/ou menor massa específica resulta em substancial aprimoramento da qualidade fisiológica.

Os lotes de sementes de cafeeiro são normalmente constituídos por diferentes tipos de sementes, em intensidade variável em função da espécie, da cultivar e das condições de produção. Embora haja predominância de sementes do tipo chato (sementes normais), ocorrem também sementes mocas, conchas e triangulares, em proporções determinadas pelo genótipo (cultivar) e sua interação com o ambiente (Mendes e BACCHI, 1940). Essas condições, associadas ao processo de extração das sementes, podem afetar a qualidade fisiológica, exigindo cuidados especiais na produção de sementes de café, uma vez que nem todos os tipos de sementes que o cafeeiro produz podem ser apropriados para a propagação da espécie (CASTILlO, 1957; CARVAlHo et al., 1983), principalmente devido ao diferencial de vigor que existe entre as sementes de um mesmo lote.

Outro fator que interfere diretamente na qualidade fisiológica das sementes de café é o teor de água. Segundo Illy $\left({ }^{5}\right)$, as sementes de café plenamente maduras apresentam parede celular bastante espessa que atua como barreira ao movimento de água no interior das sementes. Para Gromo et al. (2005), a

$\left({ }^{5}\right)$ ILLY, E. A visão do importador do café brasileiro. In: 2. ${ }^{\circ}$ Simpósio Internacional de Café. Instituto Agronômico, Campinas (SP), 2002. integridade do endocarpo também pode interferir na velocidade de perda de água durante a secagem. Assim, se as sementes estiverem imaturas, deterioradas ou com endocarpo danificado, poderão secar mais rapidamente do que as sementes maduras ou com endocarpo intacto.

Portanto, além de adotar procedimentos que minimizem as danificações mecânicas durante o processo de extração das sementes, é necessário efetuar rigoroso monitoramento e controle do teor de água durante o processo de secagem, a fim de diminuir os riscos de perda de qualidade advindos de secagem excessiva; segundo BACCHI (1955), a diminuição do teor de água para níveis inferiores a 10\% conduz à perda irreversível do potencial fisiológico das sementes de café.

Observa-se que o tamanho e a massa da semente são fortes indicativos da sua qualidade fisiológica, revelando relação direta com o vigor e desenvolvimento inicial das plântulas, cujas sementes de menor tamanho e/ou menor densidade, dentro de um mesmo lote, tendem a ter, de modo geral, germinação e vigor inferiores aos das sementes de maior tamanho ou maior densidade (PopINIGIS, 1985; Carvalho e Nakagawa, 2000). Segundo Castro (1960), o tamanho da semente só deve ser considerado como fator limitante à propagação do cafeeiro quando for muito inferior ao tamanho médio das sementes do lote, pois, mesmo com formato, tamanho e massas distintas entre si, os diferentes tipos de sementes presentes no lote possuem carga genética idêntica.

Estudando a influência do tamanho da semente no crescimento de plântulas de cafeeiro, Osorio e CASTILLO (1969) verificaram que a massa da semente foi fator determinante, em que o incremento de matéria seca e área foliar das plântulas foi proporcional à massa do endosperma. Da mesma forma, CARVAlHo e SAlLES (1957) e BARRos e Miguel (1992) verificaram que sementes grandes e pesadas proporcionaram germinação e taxa de crescimento superiores aos de sementes pequenas, porém com menor velocidade de emergência de plântulas. Portanto, considerando-se que o tamanho da semente do cafeeiro é definido em função do desenvolvimento normal de todos os componentes dos frutos (DEDECCA, 1957 e LEON e FourNIER, 1962) e que o endosperma é o principal tecido de reserva dessas sementes, é esperado que haja algum efeito de tamanho e massa das sementes no vigor e no desenvolvimento inicial das plântulas.

Em estudo de beneficiamento de sementes de cafeeiro arábica em máquina de ventiladores e peneiras e mesa densimétrica, Giomo et al. (2001) verificaram que a classificação das sementes exclusivamente pelo tamanho pode não ser suficiente para garantir boa eficiência no aprimoramento da qualidade dos lotes, uma vez que as peneiras são 
normalmente selecionadas com base nas dimensões externas das sementes, ou seja, comprimento, largura e espessura de sementes envolvidas pelo endocarpo.

Essa condição foi confirmada por FAVARIN et al. (2003), ao verificarem que a separação das sementes de café apenas por tamanho não proporcionou adequada estimativa do potencial fisiológico de sementes destinadas à produção de mudas. Da mesma forma, Araújo et al. (2004) verificaram que, na fração do lote retida na peneira $22 / 64$ de polegada, apenas $1,5 \%$ das sementes continuaram nessa mesma classe de tamanho após a remoção do pergaminho, indicando que, de fato, existe grande espaço vazio entre o endosperma e o endocarpo, pelo menos para as sementes graúdas.

Giomo et al. $(2004 ; 2005)$ avaliaram os efeitos do beneficiamento em máquina de ventiladores e peneiras e mesa densimétrica na qualidade de sementes de café Catuaí Amarelo e verificaram que esses equipamentos, trabalhando isoladamente ou em conjunto, foram eficazes para a separação e remoção de sementes com baixa qualidade fisiológica, promovendo o aprimoramento da qualidade do lote. Segundo os autores, as sementes pequenas, retidas na peneira 18/64 de polegada e as sementes de baixa densidade, oriundas da descarga inferior da mesa densimétrica, eram de qualidade fisiológica inferior à das sementes graúdas e pesadas.

De acordo com a literatura, verifica-se a efetividade da máquina de ventiladores e peneiras e da mesa densimétrica para separar e classificar sementes de inúmeras espécies agrícolas, segundo o tamanho e a massa específica, com reflexos positivos no desempenho fisiológico das sementes, sobretudo sobre a germinação e o vigor, evidenciando a importância do beneficiamento mecanizado para o aprimoramento da qualidade dos lotes de sementes. O objetivo deste trabalho foi verificar os efeitos do beneficiamento em máquina de pré-limpeza, máquina de ventiladores e peneiras e mesa densimétrica na qualidade fisiológica de sementes de cafeeiro arábica (Coffea arabica L.), cultivar Catuaí Amarelo IAC 62.

\section{MATERIAL E MÉTODOS}

A pesquisa foi desenvolvida no Instituto Agronômico (IAC), em Campinas (SP), utilizando-se um lote de sementes de café Catuaí Amarelo IAC 62, proveniente de campo de produção de sementes do Pólo Regional de Desenvolvimento Tecnológico dos Agronegócios do Nordeste Paulista, localizado em Mococa (SP). A extração das sementes foi feita por processamento via úmida de frutos completamente maduros, no estado cereja, de acordo com os procedimentos citados por SIERRA et al. (1990) e SILVA (2000).

A remoção da mucilagem foi feita por fermentação natural durante 24 horas, conforme citado por Dias e BARros (1993). Após a degomagem, as sementes foram pré-secadas ao sol durante 4 horas e, em seguida, colocadas em bandejas com fundo telado, onde continuaram secando, à sombra, até atingirem teor de água de aproximadamente 30\% (base úmida). Posteriormente, as sementes foram beneficiadas na Unidade de Beneficiamento de Sementes do IAC, em diversas combinações da máquina de pré-limpeza, máquina de ventiladores e peneiras (limpeza e classificação) e mesa densimétrica, de acordo com os critérios propostos por GREGG e FAGUNDES (1975) e VAUGHAN et al. (1976).

A máquina de pré-limpeza foi equipada com as peneiras $26 / 64$ de polegada $(10,32 \mathrm{~mm})$ na posição superior (desfolha) e $9 / 64 \times 3 / 4$ de polegada $(3,57 \mathrm{~mm}$ x 19,05 mm) na inferior (peneiração), aproveitandose do lote a fração que ficou retida na peneira inferior. A máquina de ventiladores e peneiras foi equipada com peneiras de orifícios oblongos intercaladas com peneiras de orifícios circulares, na seguinte seqüência: $15 / 64 \times 3 / 4$ de polegada $(5,95 \mathrm{~mm} \times 19,05 \mathrm{~mm}) ; 22 / 64$ de polegada $(8,73 \mathrm{~mm}) ; 20 / 64$ de polegada $(7,94 \mathrm{~mm})$; $13 / 64 \times 3 / 4$ de polegada $(5,16 \mathrm{~mm} \times 19,05 \mathrm{~mm})$ e $18 /$ 64 de polegada $(7,14 \mathrm{~mm})$. A mesa densimétrica foi utilizada com a região de descarga dividida em quatro seções: superior com $20 \mathrm{~cm}$ de extensão, intermediária-superior com $30 \mathrm{~cm}$, intermediáriainferior com $40 \mathrm{~cm}$ e inferior com $10 \mathrm{~cm}$.

Foram obtidos vinte tratamentos nas diversas etapas do beneficiamento, conforme descrito a seguir: $T_{1}$ : sementes do lote original $(\mathrm{O}) ; \mathbf{T}_{2}$ : sementes escolhidas a mão (EM); $\mathbf{T}_{3}$ : sementes da máquina de pré-limpeza (PL); $\mathbf{T}_{4}, \mathbf{T}_{5}, \mathbf{T}_{6}$ e $\mathbf{T}_{7}$ : sementes coletadas nas descargas superior (S), intermediária-superior (IS), intermediária-inferior (II) e inferior (I) da mesa densimétrica, respectivamente; $T_{8}, T_{9}, T_{10}, T_{11}$ e $T_{12}$ : sementes coletadas nas peneiras $15 \times 3 / 4$ (P15), 22 (P22), 20 (P20), $13 \times$ 33/4 (P13) e 18 (P18) da máquina de ventiladores e peneiras, respectivamente; $T_{13}, T_{14}, T_{15}$ e $\mathbf{T}_{16}$ : sementes da peneira 22 coletadas nas descargas superior (P22S), intermediária-superior (P22IS), intermediária-inferior (P22II) e inferior (P22I) da mesa densimétrica, respectivamente; $T_{17}, T_{18}, T_{19}$ e $T_{20}$ : sementes da peneira 20 coletadas nas descargas superior (P20S), intermediária-superior (P20IS), intermediária-inferior (P20II) e inferior (P20I) da mesa densimétrica respectivamente.

Para avaliação da qualidade das sementes foram realizados os seguintes testes e determinações: 
a) Teor de água: determinado em estufa a 105 $\pm 3{ }^{\circ} \mathrm{C}$ por 24 horas utilizando-se duas amostras de 25 sementes com endocarpo para cada repetição. Os resultados, em porcentagem, foram calculados com base na massa de sementes úmidas (bu), conforme as recomendações descritas nas Regras Para Análise de Sementes (BRASIL, 1992).

b) Teste de germinação: realizado à temperatura constante de $30^{\circ} \mathrm{C}$, na presença de luz, com duas amostras de 50 sementes sem endocarpo por repetição, sendo quatro repetições por tratamento. Utilizou-se como substrato papel toalha "germitest" umedecido com quantidade de água equivalente a 2,5 vezes a sua massa, conforme as recomendações descritas nas Regras Para Análise de Sementes (BRASIL, 1992). Foram consideradas normais as plântulas em que havia raiz primária com comprimento mínimo de $4 \mathrm{~mm}$, conforme os critérios propostos por HUXLEY (1965). A soma do número de plântulas normais dos dois rolos constituiu o valor médio representativo da porcentagem de germinação de cada repetição.

c) Primeira contagem da germinação: determinada juntamente com o teste de germinação, consistiu na contagem de plântulas normais no décimo quinto dia após a instalação do teste, conforme método descrito por NAKAGAWA (1999). O valor médio da porcentagem de germinação de cada repetição foi representado pela soma do número de plântulas normais computadas nos dois rolos;

d) Teste de envelhecimento acelerado: realizado de acordo com método descrito por Marcos FilHo (1999). Amostras de aproximadamente 250 sementes sem endocarpo, de cada repetição, foram uniformemente distribuídas sobre tela de aço inoxidável em gerbox contendo no fundo 40 mililitros de água destilada. Os gerbox foram colocados em câmara do tipo BOD e mantidos por 72 horas à temperatura de $42^{\circ} \mathrm{C}$ e umidade relativa do ar próxima a $100 \%$. Após esse período, as sementes foram submetidas ao teste de germinação e o vigor foi expresso pela porcentagem de plântulas normais obtida no décimo quinto dia após a instalação do teste;

e) Velocidade de emergência de plântulas: avaliada em casa de vegetação, de acordo com a metodologia descrita por NAKAGAWA (1994), com quatro repetições por tratamento. Foram semeadas em solo 50 sementes com endocarpo para cada repetição, a uma profundidade de 1 centímetro e em sulcos espaçados de 15 centímetros. As contagens foram realizadas a cada sete dias, desde o início da emergência (62 dias após a semeadura) até a paralisação da emergência de plântulas na população (97 dias após a semeadura). Em cada contagem, computaram-se as plântulas que atingiram, no mínimo, o estádio de folhas cotiledonares não expandidas (palito-de-fósforo), calculando-se o índice de velocidade de emergência de plântulas conforme os critérios propostos por MAGUIRE (1962);

f) Porcentagem de emergência de plântulas: avaliada juntamente com o teste de velocidade de emergência de plântulas, de acordo com método descrito por NAKAgawa (1994). A contagem de plântulas foi feita quando constatada a paralisação de emergência de plântulas na população, aos 97 dias após a semeadura. Para o cálculo da porcentagem de emergência computou-se o número total de plântulas que atingiram, no mínimo, o estádio "palito-defósforo";

g) Altura de plântulas: determinada no fim do teste de emergência de plântulas, segundo a método citado por NAKAGAWA (1999). A altura da plântula foi representada pela média aritmética dos valores individuais do comprimento do hipocótilo, obtidos na população de plântulas, considerando-se a distância entre o ponto de inserção de raízes e o ponto de inserção das folhas cotiledonares. Os resultados foram expressos em milímetros (mm), com uma casa decimal;

h) Massa de matéria seca de plântulas: as plântulas que atingiram o estádio "palito-defósforo", no fim do teste de emergência, tiveram o sistema radicular eliminado, foram acondicionadas em sacos de papel e em seguida colocadas para secar em estufa com circulação de ar à temperatura de $60{ }^{\circ} \mathrm{C}$, onde permaneceram até atingir massa constante, de acordo com a método descrito por Nakagawa (1994). A massa média de matéria seca foi obtida dividindo-se a massa total registrada pelo número de plântulas coletadas, sendo os resultados expressos em miligramas por plântula $\left(\mathrm{mg}\right.$ planta $\left.^{-1}\right)$;

i) Altura de mudas: as mudas foram produzidas em viveiro, de acordo com os procedimentos citados por GUIMARÃES et al. (1998). Sementes pré-germinadas à temperatura de $28^{\circ} \mathrm{C}$, até o início da emissão da raiz primária, foram semeadas à profundidade de $1 \mathrm{~cm}$ em tubetes de polipropileno contendo $120 \mathrm{~mL}$ de substrato "Plantmax-café", sendo 45 tubetes para cada repetição. A altura das mudas foi avaliada aos 156 dias após a emergência, quando na maioria das plantas havia quatro pares de folhas definitivas, considerando-se a distância entre o ponto basal de inserção de raízes e o ponto apical de inserção do último par de folhas. A altura foi calculada pela média aritmética dos valores obtidos em dez plantas da área central de cada parcela, sendo os resultados expressos em centímetros (cm); 
j) Massa de matéria seca de mudas: após a medição da altura, as plantas tiveram o sistema radicular eliminado, foram colocadas em sacos de papel e levadas para secar em estufa com circulação de ar à temperatura de $60^{\circ} \mathrm{C}$, onde permaneceram até atingir massa constante, de acordo com a método descrito por NAKAGAWA (1994). A massa de matéria seca foi determinada em balança com precisão de 0,01 grama e a massa média, obtida dividindo-se a massa total pelo número de plantas avaliadas, sendo os resultados expressos em miligramas por planta (mg planta $^{-1}$ ).

Os resultados foram analisados estatisticamente, considerando-se o delineamento de blocos ao acaso com vinte tratamentos e quatro repetições. As análises foram feitas com base nas recomendações de Mischan e PINHO (1996), utilizandose o software Statistical Analyses System (SAS). Os dados originais, obtidos em porcentagem, foram transformados em arco seno de $(x / 100)^{1 / 2}$ e submetidos à análise de variância. A análise dos dados foi feita separadamente para cada teste e os valores médios dos tratamentos, para cada variável, foram comparados pelo teste de Tukey ao nível de $5 \%$.

\section{RESULTADOS E DISCUSSÃO}

A determinação do teor de água proporcionou melhor compreensão dos efeitos causados pelo beneficiamento mecanizado na qualidade fisiológica das sementes de café. Conforme os resultados apresentados na tabela 1, observa-se que nas frações obtidas na descarga inferior (I, P22I e P20I) havia teor de água inferior ao das sementes obtidas nas descargas superior (S, P22S e P20S) e intermediária-superior (IS) da mesa densimétrica. Esses resultados demonstram que houve eficiência da mesa densimétrica em deslocar as sementes mais secas para a descarga inferior, como conseqüência da sua menor massa específica em relação às sementes mais úmidas, porém sob algum efeito do teor de água que pode ter interferido na estratificação das sementes, corroborando resultados de GIOMO et al. $(2001 ; 2004 ; 2005)$.

Tabela 1. Valores médios de teor de água, germinação, primeira contagem da germinação e envelhecimento acelerado, em porcentagem, de sementes de café Catuaí Amarelo IAC 62, em função da forma de beneficiamento

\begin{tabular}{|c|c|c|c|c|}
\hline Tratamentos & Teor de água & Germinação & Primeira contagem & Envelhecimento acelerado \\
\hline & & & & \\
\hline $\mathrm{T}_{1}(\mathrm{O})$ & $14,03 \mathrm{~cd}$ & 83 cde & $48 \mathrm{~cd}$ & $80 \mathrm{ab}$ \\
\hline $\mathrm{T}_{2}(\mathrm{EM})$ & $22,61 \mathrm{a}$ & $93 \mathrm{ab}$ & $61 \mathrm{abc}$ & $76 \mathrm{abc}$ \\
\hline $\mathrm{T}_{3}(\mathrm{PL})$ & $16,57 \mathrm{bcd}$ & $91 \mathrm{abc}$ & $59 \mathrm{abc}$ & $79 \mathrm{ab}$ \\
\hline $\mathrm{T}_{4}(\mathrm{~S})$ & $20,24 \mathrm{ab}$ & $94 \mathrm{a}$ & $69 \mathrm{ab}$ & $85 \mathrm{a}$ \\
\hline $\mathrm{T}_{5}$ (IS) & $18,63 \mathrm{abc}$ & $93 \mathrm{ab}$ & $63 \mathrm{abc}$ & $78 \mathrm{abc}$ \\
\hline $\mathrm{T}_{6}(\mathrm{II})$ & $14,68 \mathrm{bcd}$ & $94 \mathrm{a}$ & $66 \mathrm{abc}$ & $78 \mathrm{abc}$ \\
\hline $\mathrm{T}_{7}(\mathrm{I})$ & $12,26 \mathrm{~d}$ & $80 \mathrm{e}$ & $35 \mathrm{~d}$ & $69 \mathrm{bc}$ \\
\hline $\mathrm{T}_{8}(\mathrm{P} 15)$ & $15,89 \mathrm{bcd}$ & 90 abcd & $60 \mathrm{abc}$ & $73 \mathrm{abc}$ \\
\hline $\mathrm{T}_{9}(\mathrm{P} 22)$ & $14,25 \mathrm{~cd}$ & $91 \mathrm{abc}$ & $53 \mathrm{bcd}$ & $77 \mathrm{abc}$ \\
\hline $\mathrm{T}_{10}(\mathrm{P} 20)$ & $15,25 \mathrm{bcd}$ & $91 \mathrm{abc}$ & $61 \mathrm{abc}$ & $80 \mathrm{ab}$ \\
\hline $\mathrm{T}_{11}$ (P13) & $17,93 \mathrm{abcd}$ & 90 abcd & $67 \mathrm{abc}$ & $75 \mathrm{abc}$ \\
\hline $\mathrm{T}_{12}(\mathrm{P} 18)$ & $16,34 \mathrm{bcd}$ & 86 bcde & $65 \mathrm{abc}$ & $82 \mathrm{ab}$ \\
\hline $\mathrm{T}_{13}(\mathrm{P} 22 \mathrm{~S})$ & $20,64 \mathrm{ab}$ & $94 \mathrm{a}$ & $59 \mathrm{abc}$ & $82 \mathrm{ab}$ \\
\hline $\mathrm{T}_{14}$ (P22IS) & $17,39 \mathrm{abcd}$ & $93 \mathrm{ab}$ & $66 \mathrm{abc}$ & $82 \mathrm{ab}$ \\
\hline $\mathrm{T}_{15}(\mathrm{P} 22 \mathrm{II})$ & $13,96 \mathrm{~cd}$ & $91 \mathrm{abc}$ & $53 \mathrm{bcd}$ & 73 abc \\
\hline $\mathrm{T}_{16}(\mathrm{P} 22 \mathrm{I})$ & $12,78 \mathrm{~cd}$ & $81 \mathrm{de}$ & $38 \mathrm{~d}$ & $63 \mathrm{~cd}$ \\
\hline $\mathrm{T}_{17}(\mathrm{P} 20 \mathrm{~S})$ & $17,77 \mathrm{abcd}$ & $95 \mathrm{a}$ & $70 \mathrm{ab}$ & $79 \mathrm{abc}$ \\
\hline $\mathrm{T}_{18}$ (P20IS) & $15,26 \mathrm{bcd}$ & $94 \mathrm{a}$ & $74 \mathrm{a}$ & $68 \mathrm{bcd}$ \\
\hline $\mathrm{T}_{19}$ (P20II) & $13,47 \mathrm{~cd}$ & $93 a b$ & $65 \mathrm{abc}$ & $67 \mathrm{bcd}$ \\
\hline $\mathrm{T}_{20}$ (P2OI) & $12,47 \mathrm{~d}$ & $79 \mathrm{e}$ & $38 \mathrm{~d}$ & $53 \mathrm{~d}$ \\
\hline MÉDIA & 16,12 & 90,09 & 58,64 & 75,04 \\
\hline $\mathrm{CV}$ & 6,34 & 2,27 & 6,87 & 4,28 \\
\hline
\end{tabular}

Médias seguidas de mesma letra, na coluna, não diferem significativamente entre si pelo teste de Tukey a $5 \%$ de probabilidade.

$\mathrm{T}_{1}(\mathrm{O})$ : sementes do lote original; $\mathrm{T}_{2}(\mathrm{EM})$ : sementes escolhidas a mão; $\mathrm{T}_{3}(\mathrm{PL})$ : sementes da máquina de pré-limpeza; $\mathrm{T}_{4}(\mathrm{~S}), \mathrm{T}_{5}$ (IS), $\mathrm{T}_{6}$ (II) e $\mathrm{T}_{7}$ (I): sementes coletadas nas descargas superior, intermediária-superior, intermediária-inferior e inferior da mesa densimétrica respectivamente; $\mathrm{T}_{8}$ (P15), $\mathrm{T}_{9}$ (P22), $\mathrm{T}_{10}$ (P20), $\mathrm{T}_{11}$ (P13) e $\mathrm{T}_{12}$ (P18): sementes coletadas nas peneiras $15 \times 3 / 4,22,20,13 \times 3 / 4$ e 18 da máquina de ventiladores e peneiras respectivamente; $\mathrm{T}_{13}$ (P22S), $\mathrm{T}_{14}$ (P22IS), $\mathrm{T}_{15}$ (P22II) e $\mathrm{T}_{16}$ (P22I): sementes da peneira 22 coletadas nas descargas superior, intermediáriasuperior, intermediária-inferior e inferior da mesa densimétrica respectivamente; $T_{17}$ (P20S), $T_{18}$ (P20IS), $T_{19}$ (P20II) e $T_{20}$ (P20I): sementes da peneira 20 coletadas nas descargas superior, intermediária-superior, intermediária-inferior e inferior da mesa densimétrica respectivamente. 
Os resultados do teste de germinação, apresentados na tabela 1 indicam que o beneficiamento foi favorável à melhoria da qualidade fisiológica das sementes, proporcionando acréscimos de 10 a 12 pontos percentuais na germinação, que subiu de $83 \%$, no lote original, para $93 \%$ a $95 \%$ em alguns dos melhores tratamentos. As sementes pequenas ou mais leves, coletadas na peneira inferior da máquina de ventiladores e peneiras (P18) e na descarga inferior da mesa densimétrica (I, P22I e P20I), proporcionaram os mais baixos valores de germinação, igualando-se às sementes não beneficiadas do lote original $(\mathrm{O})$. Ressalta-se que as sementes dos tratamentos I, P22I e P20I foram as que também tiveram os menores valores de teor de água. As sementes obtidas na escolha manual (EM) e nas descargas superior (S, P22S e P20S), intermediária-superior (IS, P22IS e P20IS) e intermediária-inferior (II e P20II) da mesa densimétrica proporcionaram os maiores valores de germinação, porém não diferiram significativamente das sementes dos tratamentos PL, P15, P22, P20, P13 e P22II, com valores intermediários de germinação.

As frações com sementes maiores ou mais pesadas tenderam a proporcionar germinação superior à das sementes menores ou mais leves, porém nem sempre diferiram estatisticamente. A concentração de sementes mais leves, na descarga inferior da mesa densimétrica, ainda que possa ter ocorrido alguma interferência do teor de água na estratificação das sementes, pode explicar, em parte, a menor porcentagem de germinação, uma vez que as sementes com maior densidade têm, freqüentemente, germinação superior à das sementes com menor densidade, conforme citado por Popinigis (1985). Resultados semelhantes foram citados por VIEIRA et al. (1995) com sementes de arroz, por FelDMANN e Toledo (1979) com sementes de soja, por BAUDET e MISRA (1991) com sementes de milho, por Lollato e Silva (1984) e Buitrago et al. (1991) com sementes de feijão, por Alexandre e Silva (2001) com sementes de ervilhacacomum e por GIOMO et al. (2001), FAVARIN et al. (2003), Araújo et al. (2004) e Giomo et al. (2004) com sementes de café.

Verifica-se nas sementes do lote em estudo alta qualidade fisiológica, com germinação média de $90 \%$, e nos tratamentos P15 e P13, constituídos por $70 \%$ e $87 \%$ de sementes mocas, respectivamente, a germinação foi similar à das sementes chatas, corroborando os resultados de Giomo et al. (2001; 2004). Pelos resultados do teste de germinação, todos os tratamentos enquadraram-se no padrão de germinação $(70 \%)$ para sementes de café nos Estados de São Paulo (SÃo Paulo, 1997) e Minas Gerais (Instituto Mineiro de Agropecuária, 2000).
Os resultados relacionados na tabela 1 indicam que houve acréscimo significativo nos percentuais de vigor das sementes na primeira contagem da germinação, após o beneficiamento. As sementes classificadas por tamanho, na peneira 20, e separadas nas descargas superior (P20S) e intermediária-superior (P20IS) da mesa densimétrica foram as de mais altos valores de vigor, diferenciandose das sementes não beneficiadas do lote original (O). Já nas sementes com menor densidade das frações obtidas na descarga inferior da mesa densimétrica (I, P22I e P20I), os valores de vigor foram mais baixos, igualando-se às sementes do lote original $(\mathrm{O})$.

Esses resultados revelam que, paralelamente à concentração de sementes com menores valores de teor de água e massa específica, na descarga inferior da mesa densimétrica, há a possibilidade de separar sementes de café menos vigorosas nessa descarga, indicando efeito positivo da mesa densimétrica na separação de frações com qualidade fisiológica distinta, confirmando as considerações feitas por Popinigis (1985) e Alexandre e Silva (2001) com sementes de ervilhaca-comum e por Giomo et al. (2001), Araújo et al. (2004) e Giomo et al. (2004) com sementes de café.

As sementes classificadas somente por tamanho proporcionaram valores intermediários de vigor na primeira contagem da germinação, porém sem diferir significativamente das sementes sem beneficiamento $(\mathrm{O})$, das sementes escolhidas manualmente (EM) e das sementes beneficiadas em máquina de pré-limpeza (PL). O desempenho das sementes mocas (P15 e P13) foi similar ao das sementes chatas, evidenciando que não há razão para serem descartadas dos lotes de sementes de café. Verifica-se, portanto, que os equipamentos utilizados no beneficiamento causaram efeitos diferenciados na qualidade fisiológica das sementes, sendo o desempenho da mesa densimétrica superior ao da máquina de ventiladores e peneiras para a separação de sementes com diferentes níveis de qualidade, corroborando resultados constatados por Lollato e Silva (1984), Ahrens e Krzyzanowski (1994), Ahrens e KrZYZANOWSKI (1998) e Giomo et al. (2001). Embora em todos os tratamentos tenham se observado sementes com germinação acima de $70 \%$, ressalta-se que, para maior aprimoramento da qualidade do lote, as frações I, P22I e P20I poderiam ser descartadas devido ao baixo vigor verificado na primeira contagem da germinação.

Os resultados do teste de envelhecimento acelerado (Tabela 1) indicam nas frações obtidas na descarga inferior da mesa densimétrica (I, P22I e P20I) sementes com vigor inferior ao das sementes não 
beneficiadas do lote original $(\mathrm{O})$, confirmando o pior desempenho observado nessas sementes nos testes de germinação e na primeira contagem da germinação. Dessa forma, ressalta-se a importância da mesa densimétrica para a separação de sementes de café com qualidade fisiológica inferior, cujo descarte seria benéfico para o aprimoramento da qualidade do lote.

Observa-se, pelos resultados do teste de envelhecimento acelerado, que as sementes estavam com vigor médio de $75 \%$ e nos tratamentos P15 e P13, constituídos por $70 \%$ e $87 \%$ de sementes mocas, os valores de vigor foram de $73 \%$ e $75 \%$ respectivamente, igualando-se aos tratamentos constituídos predominantemente por sementes chatas. Assim, como no teste de germinação, não há necessidade de descartar as sementes mocas dos lotes de sementes de cafeeiro arábica.
Constatou-se que as frações utilizadas na alimentação da mesa densimétrica deram origem a outras frações cujas sementes com vigor decrescente, no sentido da descarga superior para a inferior, possibilitam a separação de tratamentos com níveis diferenciados de vigor. Nestas circunstâncias, as frações deslocadas para a descarga inferior da mesa densimétrica, e, portanto, com menor massa específica, são sementes menos vigorosas, reforçando os resultados do teste de germinação e corroborando resultados obtidos por FELDMANN e TOLEDO (1979) com sementes de soja, por Lollato e Silva (1984) com sementes de feijão, por BAUdET e MisRa (1991) com sementes de milho, por VieIra et al. (1995) com sementes de arroz, por Alexandre e Silva (2001) com sementes de ervilhaca-comum e por Giomo et al. (2001), Araújo et al. (2004) e Giomo et al. (2004) com sementes de café.

Tabela 2. Valores médios de emergência de plântulas (EP), índice de velocidade de emergência de plântulas (IVE), altura de plântulas (AP), massa de matéria seca de plântulas (MSP), altura de muda (AM) e massa de matéria seca de mudas (MSM) de café Catuaí Amarelo IAC 62, em função da forma de beneficiamento

\begin{tabular}{|c|c|c|c|c|c|c|}
\hline Tratamentos & $\mathrm{EP}$ & IVE & $\mathrm{AP}$ & MSP & $\mathrm{AM}$ & MSM \\
\hline & $\%$ & & $\mathrm{~mm}$ & $\mathrm{mg}_{\text {planta }}{ }^{-1}$ & $\mathrm{~cm}$ & mg planta $^{-1}$ \\
\hline $\mathrm{T}_{1}(\mathrm{O})$ & 90 a & $7,8 \mathrm{a}$ & $48,8 \mathrm{ab}$ & 71,8 cdef & 28,6 a & $1077,2 \mathrm{ab}$ \\
\hline $\mathrm{T}_{2}(\mathrm{EM})$ & 89 a & $7,9 \mathrm{a}$ & $48,8 \mathrm{ab}$ & 74,3 bcde & $28,7 \mathrm{a}$ & $997,5 \mathrm{ab}$ \\
\hline $\mathrm{T}_{3}(\mathrm{PL})$ & $83 \mathrm{~b}$ & $7,4 \mathrm{ab}$ & $48,7 \mathrm{ab}$ & $77,1 \mathrm{abcd}$ & 29,2 a & $1064,0 \mathrm{ab}$ \\
\hline $\mathrm{T}_{4}(\mathrm{~S})$ & $92 \mathrm{a}$ & $8,3 \mathrm{a}$ & $50,1 \mathrm{ab}$ & $85,4 \mathrm{ab}$ & 28,9 a & $1090,5 \mathrm{ab}$ \\
\hline $\mathrm{T}_{5}$ (IS) & $92 \mathrm{a}$ & $8,2 \mathrm{a}$ & $49,3 \mathrm{ab}$ & $79,7 \mathrm{abcd}$ & $28,4 \mathrm{a}$ & $1045,2 \mathrm{ab}$ \\
\hline $\mathrm{T}_{6}(\mathrm{II})$ & $86 a b$ & $7,5 \mathrm{a}$ & $50,5 \mathrm{ab}$ & 79,7 abcd & $28,4 \mathrm{a}$ & $985,2 \mathrm{ab}$ \\
\hline $\mathrm{T}_{7}(\mathrm{I})$ & $83 \mathrm{~b}$ & $7,3 \mathrm{ab}$ & $49,4 \mathrm{ab}$ & 74,2 bcde & $28,5 \mathrm{a}$ & $1038,0 \mathrm{ab}$ \\
\hline $\mathrm{T}_{8}(\mathrm{P} 15)$ & $91 \mathrm{a}$ & $8,0 \mathrm{a}$ & $51,8 \mathrm{a}$ & $81,8 \mathrm{abc}$ & $29,0 \mathrm{a}$ & $1107,0 \mathrm{ab}$ \\
\hline $\mathrm{T}_{9}(\mathrm{P} 22)$ & 89 a & 7,8 a & $52,0 \mathrm{a}$ & $85,6 \mathrm{ab}$ & $29,4 \mathrm{a}$ & $1110,8 \mathrm{a}$ \\
\hline $\mathrm{T}_{10}(\mathrm{P} 20)$ & $88 \mathrm{ab}$ & $7,8 \mathrm{a}$ & $51,4 \mathrm{ab}$ & $79,5 \mathrm{abcd}$ & $28,7 \mathrm{a}$ & $1037,0 \mathrm{ab}$ \\
\hline $\mathrm{T}_{11}(\mathrm{P} 13)$ & $87 \mathrm{ab}$ & $7,6 \mathrm{a}$ & $49,8 \mathrm{ab}$ & 68,1 def & $27,8 \mathrm{a}$ & $942,3 \mathrm{~b}$ \\
\hline $\mathrm{T}_{12}(\mathrm{P} 18)$ & $84 \mathrm{ab}$ & 7,6 a & $46,2 \mathrm{~b}$ & $58,6 \mathrm{f}$ & $28,5 \mathrm{a}$ & $1005,5 \mathrm{ab}$ \\
\hline $\mathrm{T}_{13}(\mathrm{P} 22 \mathrm{~S})$ & $88 \mathrm{ab}$ & $7,6 \mathrm{a}$ & $51,9 \mathrm{a}$ & 90,3 a & $29,2 \mathrm{a}$ & $1160,0 \mathrm{a}$ \\
\hline $\mathrm{T}_{14}$ (P22IS) & $87 \mathrm{ab}$ & $7,6 \mathrm{a}$ & $53,7 \mathrm{a}$ & 88,8 a & $29,3 \mathrm{a}$ & $1092,8 \mathrm{ab}$ \\
\hline $\mathrm{T}_{15}(\mathrm{P} 22 \mathrm{II})$ & 90 a & $8,0 \mathrm{a}$ & $52,1 \mathrm{a}$ & 88,6 a & 29,3 a & $1089,2 \mathrm{ab}$ \\
\hline $\mathrm{T}_{16}(\mathrm{P} 22 \mathrm{I})$ & $85 \mathrm{ab}$ & $7,4 \mathrm{ab}$ & $48,9 \mathrm{ab}$ & 78,0 abcd & 28,5 a & $1046,8 \mathrm{ab}$ \\
\hline $\mathrm{T}_{17}(\mathrm{P} 20 \mathrm{~S})$ & 90 a & $7,8 \mathrm{a}$ & $52,1 \mathrm{a}$ & $79,3 \mathrm{abcd}$ & $29,0 \mathrm{a}$ & $1099,8 \mathrm{ab}$ \\
\hline $\mathrm{T}_{18}$ (P20IS) & 89 a & $7,8 \mathrm{a}$ & $49,5 \mathrm{ab}$ & 77,2 abcd & 29,3 a & $1098,0 \mathrm{ab}$ \\
\hline $\mathrm{T}_{19}(\mathrm{P} 20 \mathrm{II})$ & $88 \mathrm{ab}$ & $7,4 \mathrm{ab}$ & $50,8 \mathrm{ab}$ & 72,5 bcde & 28,7 a & $1041,2 \mathrm{ab}$ \\
\hline $\mathrm{T}_{20}(\mathrm{P} 20 \mathrm{I})$ & $79 \mathrm{~b}$ & $6,5 \mathrm{~b}$ & $49,7 \mathrm{ab}$ & 63,4 ef & 28,6 a & $1076,2 \mathrm{ab}$ \\
\hline MÉDIA & 87,8 & 7,67 & 50,29 & 77,69 & 28,81 & 1060,2 \\
\hline $\mathrm{CV}$ & 5,01 & 4,99 & 4,21 & 6,57 & 2,48 & 7,61 \\
\hline
\end{tabular}

Médias seguidas de mesma letra, na coluna, não diferem significativamente entre si pelo teste de Tukey a $5 \%$ de probabilidade.

$\mathrm{T}_{1}(\mathrm{O})$ : sementes do lote original; $\mathrm{T}_{2}(\mathrm{EM})$ : sementes escolhidas a mão; $\mathrm{T}_{03}(\mathrm{PL})$ : sementes da máquina de pré-limpeza; $\mathrm{T}_{4}(\mathrm{~S}), \mathrm{T}_{5}(\mathrm{IS}), \mathrm{T}_{6}(\mathrm{II})$ e $\mathrm{T}_{7}(\mathrm{I})$ : sementes coletadas nas descargas superior, intermediária-superior, intermediária-inferior e inferior da mesa densimétrica respectivamente; $\mathrm{T}_{8}$ (P15), $\mathrm{T}_{9}$ (P22), $\mathrm{T}_{10}$ (P20), $\mathrm{T}_{11}$ (P13) e $\mathrm{T}_{12}$ (P18): sementes coletadas nas peneiras $15 \times 3 / 4,22,20,13 \times 3 / 4$ e 18 da máquina de ventiladores e peneiras respectivamente; $\mathrm{T}_{13}$ (P22S), $\mathrm{T}_{14}$ (P22IS), $\mathrm{T}_{15}$ (P22II) e $\mathrm{T}_{16}$ (P22I): sementes da peneira 22 coletadas nas descargas superior, intermediáriasuperior, intermediária-inferior e inferior da mesa densimétrica respectivamente; $\mathrm{T}_{17}(\mathrm{P} 20 \mathrm{~S}), \mathrm{T}_{18}$ (P20IS), $\mathrm{T}_{19}$ (P20II) e $\mathrm{T}_{20}(\mathrm{P} 20 \mathrm{I})$ : sementes da peneira 20 coletadas nas descargas superior, intermediária-superior, intermediária-inferior e inferior da mesa densimétrica respectivamente. 
Os resultados da avaliação de plântulas em solo, constantes da tabela 2 , revelam que os testes de emergência de plântulas e índice de velocidade de emergência permitiram detectar valores de vigor similares quanto às tendências de variação. Assim, as sementes sem beneficiamento $(\mathrm{O})$, as sementes escolhidas manualmente (EM), as sementes classificadas nas peneiras superiores da máquina de ventiladores e peneiras (P15 e P22) e as sementes obtidas nas descargas superior (S e P20S), intermediária-superior (IS e P20IS) e intermediáriainferior (P22II) da mesa densimétrica resultaram em maiores porcentagens de emergência de plântulas, significativamente superiores aos valores das sementes obtidas na máquina de pré-limpeza (PL) e na descarga inferior da mesa densimétrica (I e P20I), identificadas como as menos vigorosas. As sementes dos tratamentos II, P20, P13, P18, P22S, P22IS, P22I e P20II resultaram em valores intermediários, sem diferir significativamente dos tratamentos com maior ou menor vigor.

O índice de velocidade de emergência de plântulas indicou que a qualidade fisiológica das sementes classificadas na peneira 20 e deslocadas para a descarga inferior da mesa densimétrica (P20I) foi significativamente inferior à das sementes obtidas nas descargas superior e intermediária-superior. Observa-se que, apesar das sementes classificadas por tamanho e massa específica terem, por este teste, valores de vigor similares aos das sementes classificadas somente por tamanho, a mesa densimétrica permitiu deslocar para a descarga inferior as sementes menos vigorosas que, da mesma forma observada nos demais testes, corresponderam às sementes com menor massa específica. Portanto, $\mathrm{o}$ teste de emergência de plântulas em campo foi adequado para a avaliação da qualidade fisiológica das sementes de café.

Quanto à altura de plântulas, observa-se que o tratamento correspondente à peneira inferior da máquina de ventiladores e peneiras (P18) foi o de menor valor, significativamente inferior aos das frações obtidas nas maiores peneiras (P15 e P22), nas descargas superior, intermediária-superior e intermediária-inferior da peneira 22 (P22S, P22IS e P22II) e na descarga superior da peneira 20 (P20S) na mesa densimétrica. As plântulas provenientes das sementes pequenas ou mais leves tiveram menor crescimento da parte aérea, menor acúmulo de matéria seca e foram menos vigorosas que as plântulas provenientes das sementes grandes ou mais pesadas, corroborando os resultados observados por FRAZÃO et al. (1983) com sementes de guaraná, por FrAZÃo et al. (1984) com sementes de cacau, por AgUIAR et al. (1996) com sementes de pau-brasil, por CASTRO e DUTRA (1997) com sementes de leucena, por FERREIRA e TORRES (2000) com sementes de acácia-gomífera, por MARTiNs et al. (2000) com sementes de palmito-vermelho e por YosHIDA et al. (1999) e Giomo et al. (2001), FAVARIN et al. (2003), Araújo et al. (2004) e Giomo et al. (2004) com sementes de café.

$O$ beneficiamento mecanizado aprimorou efetivamente a qualidade fisiológica das sementes, proporcionando aumento significativo da massa de matéria seca de plântulas em relação às sementes sem beneficiamento $(\mathrm{O})$ e às sementes escolhidas manualmente (EM). As frações de sementes obtidas nas diversas etapas do beneficiamento proporcionaram diferentes níveis de vigor entre si, sendo alto para os tratamentos P22, S, P22S, P22IS e P22II, médio para os tratamentos PL, P15, P20, P20S, IS, P20IS, II e P22I e baixo para os tratamentos O, EM, P13, P18, P20II, I e P20I. Embora essa determinação não tenha permitido detectar diferenças significativas que possibilitassem a discriminação de qualidade entre os tratamentos com sementes na faixa de vigor intermediário, verificou-se que as sementes pequenas e leves deram origem a plantas menos vigorosas, indicando que o desenvolvimento inicial da muda foi proporcional ao conteúdo de tecidos de reserva do endosperma. Esses resultados confirmam as observações feitas por Carvalho e Salles (1957), Castro (1960), Osorio e CAstillo (1969), FrazÃo et al. (1984), Giomo et al. (2001), FAVARIN et al. (2003) e Giomo et al. (2004), destacando a importância da separação de sementes pequenas e de baixa densidade dos lotes de sementes de café a fim de se obter mudas vigorosas.

A avaliação da altura das mudas (Tabela 2) não permitiu detectar diferenças significativas entre os tratamentos. A falta de sensibilidade desse tipo de avaliação também foi verificada em estudos realizados com sementes de soja (FEldmann e Toledo, 1979), com sementes de feijão (Buitrago et al., 1991) e com sementes de ervilhaca-comum (AlEXANDre e Silva, 2001). É possível que as diferenças inicialmente existentes entre as sementes dos diversos tratamentos tenham diminuído ou desaparecido durante a fase de produção de mudas, na qual as plantas permaneceram sob condições favoráveis ao desenvolvimento por cerca de 120 dias, com indícios de que a superioridade das plântulas provenientes de sementes mais vigorosas tendeu a decrescer à medida que as plantas se desenvolveram, confirmando as observações feitas por FrAZÃo et al. (1984).

\section{CONCLUSÕES}

1. A qualidade fisiológica das sementes de café foi aprimorada à medida que o lote passou por equipamentos específicos nas diversas etapas do 
beneficiamento, culminando com a máxima qualidade na seqüência operacional completa, onde foi incluída a mesa densimétrica.

2. A mesa densimétrica, associada à máquina de ventiladores e peneiras, foi o equipamento que proporcionou a melhor separação de materiais que interferem negativamente na qualidade fisiológica das sementes de café.

3. As sementes de maior tamanho ou maior densidade são de qualidade fisiológica superior à das sementes de menor tamanho ou menor densidade; as sementes mocas graúdas são de qualidade fisiológica similar à das sementes chatas;

4. O descarte das frações do lote constituídas por sementes pequenas ou de menor densidade aprimorou significativamente a qualidade fisiológica das sementes de café, possibilitando a obtenção de lotes homogêneos e favorecendo a obtenção de mudas mais vigorosas.

\section{AGRADECIMENTOS}

Os autores agradecem aos funcionários da Unidade de Beneficiamento de Sementes e Laboratório de Análise de Sementes do Instituto Agronômico, em especial ao Pesquisador Científico Marcelo Ticelli e aos Técnicos Dirceu Borges, Ivonete Alves dos Santos e Denise Sayuri Issa, pela valiosa colaboração e auxílio na execução dos experimentos.

\section{REFERÊNCIAS}

AGUIAR, F.F.A.; KANASHIRO, S.; BARBEDO, C.J.; SEMACO, M. Influência do tamanho sobre a germinação de sementes de Caesalpinia echinata Lam. (Pau-brasil). Revista Brasileira de Sementes, Brasília, v.18, n.2, p.283-85, 1996.

AHRENS, D.C.; KRZYZANOWSKI, F.C. Efeito do beneficiamento de sementes de tremoço azul sobre as qualidades física, fisiológica e sanitária. Scientia Agricola, Piracicaba, v.55, n.2, p.242-48, 1998.

AHRENS, D.C.; KRZYZANOWSKI, F.C. O separador em espiral e a mesa gravitacional na melhoria da qualidade fisiológica de sementes de soja. Informativo ABRATES, Londrina, v.4, n.3, p.14-8, 1994.

ALEXANDRE, A.D.; SILVA, W.R. da. Mesa gravitacional e qualidade fisiológica e sanitária de sementes de ervilhaca comum (Vicia sativa L.). Revista Brasileira de Sementes, Brasília, v.23, n.1, p.167-74, 2001.

ARAÚJO, E.F.; MEIRELES, R.C.; REIS, L.S. dos; MAURI, A.L.; DAVID, A.M.S.S. Uso de peneiras e da mesa gravitacional na classificação e na qualidade de sementes de cafeeiro (Coffea arabica L.). Revista Brasileira de Armazenamento, Viçosa, Especial Café, n.8, p.24-28, 2004.
BACCHI, O. Seca da semente de café ao sol. Bragantia, Campinas, v.14, p.226-36, 1955.

BARROS, U.V.; MIGUEL, A.E. Avaliação da germinação e crescimento de plântulas de café provenientes de sementes de diferentes tamanhos, colhidas em diversas posições no ramo e na planta, em dois níveis de carga pendente. In: CONGRESSO BRASILEIRO DE PESQUISAS CAFEEIRAS, 18., 1992, Araxá. Resumos... Araxá: MARA/SNPA/PROCAFÉ, 1992. p.24-26.

BAUDET, L.; MISRA, M. Atributos de qualidade de sementes de milho beneficiadas em mesa gravitacional. Revista Brasileira de Sementes, Brasília, v.13, n.2, p.91-97, 1991.

BRASIL. Ministério da Agricultura e Reforma Agrária. Regras para análise de sementes. Brasília:SNDA/DNDV/CLAV,1992. 365p.

BUITRAGO, I.C.; VILLELA, F.A.; TILLMANN, M.A.A.; SILVA, J.B. da. Perdas e qualidade de sementes de feijão beneficiadas em máquina de ventiladores e peneiras e mesa gravitacional. Revista Brasileira de Sementes, Brasília, v.13, n.2, p.99-104, 1991.

CARVALHO, A.; COSTA, W.M.; FAZUOLI, L.C. Autoincompatibilidade, produtividade, ocorrência de sementes tipo moca e mudas anormais no café Icatu. Bragantia, Campinas, v.42, p.157-69, 1983.

CARVALHO, A.; SALLES, F.J.M. A influência do tamanho da semente de café na germinação e crescimento das mudas. Boletim Técnico da Superintendência dos Serviços do Café, v.32, n.370, p.11-20, 1957.

CARVALHO, N.M.; NAKAGAWA, J. Sementes: ciência, tecnologia e produção. 4.ed. Jaboticabal: FUNEP, 2000. 588p.

CASTILLO, J.Z. Influencia de algunos tratamientos culturales sobre la calidad del grano de café. Cenicafé, Chinchiná v.8, n.11, p.333-46, 1957.

CASTRO, F.S. Escogencia y tratamiento de la semilla de café. Agricultura Tropical, v.16, n.11, p.715-24, 1960.

CASTRO, J.R. de; DUTRA, A.S. Influência do tamanho das sementes de leucena (Leucaena leucocephala (Lam.) De Wit) cv. Cunningham na germinação e no vigor. Revista Brasileira de Sementes, Brasília, v.19, n.1, p.88-90, 1997.

DEDECCA, D.M. Anatomia e desenvolvimento ontogenético de Coffea arabica L. var. Typica Cramer. Bragantia, Campinas, n.16, p.315-55, 1957.

DELOUCHE, J.C.; POTTS, H.C. Controle de qualidade e avaliação. In:__. (Eds.). Programa de sementes: planejamento e implantação. 2.ed. Brasília: Ministério da Agricultura/ AGIPLAN, 1974. cap.V, p.74-83.

DIAS, M.C.L.L.; BARROS, A.S.R. Avaliação de métodos para remoção da mucilagem de sementes de café (Coffea arabica L.). Revista Brasileira de Sementes, Brasília, v.15, n.2, p.191-195, 1993.

FAVARIN, J.L.; COSTA, J.D.; NOVEMBRE, A.D.C.; FAZUOLI, L.C.; FAVARIN, M. da G.G.V. Características da semente em relação ao seu potencial fisiológico e a qualidade de mudas de café (Coffea arabica L.). Revista Brasileira de Sementes, Brasília, v.25, n.2, p.13-19, 2003. 
FELDMANN, R.O.; TOLEDO, F.F. de. Influência do peso e do tamanho da semente sobre a germinação, o vigor e a produção da soja (Glycine Max (L.) Merril). In: CONGRESSO BRASILEIRO DE SEMENTES, 1., 1979, Curitiba. Resumos... Brasília: ABRATES, 1979. p.28.

FERREIRA, M.G.R.; TORRES, S.B. Influência do tamanho das sementes na germinação e no vigor de plântulas de Acacia senegal (L.) Willd. Revista Brasileira de Sementes, Brasília, v.22, n.1, p.271-75, 2000.

FRAZÃO, D.A.C.; FIGUEIREDO, F.J.C.; CORRÊA, M.P.F.; OLIVEIRA, R.P. de; POPINIGIS, F. Tamanho da semente de guaraná e sua influência na emergência e no vigor. Revista Brasileira de Sementes, Brasília, v.5, n.1, p.81-91, 1983.

FRAZÃO, D.A.C.; COSTA, J.D.; CORAL, F.J.; AZEVEDO, J.A.; FIGUEIREDO, F.J.C. Influência do peso da semente no desenvolvimento e vigor de mudas de cacau. Revista Brasileira de Sementes, Brasília,v.6, n.3, p.31-9, 1984.

GIOMO, G.S.; RAZERA, L.F.; GALLO, P.B. Beneficiamento de sementes de café (Coffea arabica L.) em máquina de ar e peneiras e mesa gravitacional. In: SIMPÓSIO DE PESQUISA DE CAFÉS DO BRASIL, 2., 2001, Vitória. Anais... Brasília: MAA/CBPDC/ EMBRAPA, 2001. p.1648-1658. 1 CD-ROM.

GIOMO, G.S.; RAZERA, L.F.; GALLO, P.B. Beneficiamento e qualidade de sementes de café arábica. Bragantia, Campinas, v.63, n.2, p291-297, 2004.

GIOMO, G.S.; NAKAGAWA, J.; GALLO, P.B. Beneficiamento de sementes de café arábica e efeitos na qualidade física. In: SIMPÓSIO DE PESQUISA DOS CAFÉS DO BRASIL, 4, 2005. Anais... Londrina: MAA/CBPDC/EMBRAPA, 2005. np. 1 CD-ROM.

GREGG, B.R.; FAGUNDES, S.R.F. Manual de operações da mesa gravitacional. Brasília: Ministério da Agricultura/ AGIPLAN, 1975. 78p.

GUIMARÃES, P.T.G.; ANDRADE NETO, A.; BELINI JÚNIOR, O.; ADÃO, W.A.; SILVA, E.M. A produção de mudas de cafeeiros em tubetes. Informativo Agropecuário, Belo Horizonte, v.19, n.139, p.98-109, 1998.

HUXLEY, P.A. Coffee germination test recommendations and defective seed types. Proceedings of the International Seed Testing Association, Wageningen, v.30, n.3, p.705-14, 1965.

INSTITUTO MINEIRO DE AGROPECUÁRIA. Normas e padrões para a produção de sementes básicas e fiscalizadas de café. Anexo I da Portaria no 388, de 22 de maio de 2000.

LEON, J.; FOURNIER, L. Crecimiento y desarrollo del fruto de Coffea arabica L. Turrialba, San José, v.12, p.65-74, 1962.

LOLLATO, M.A.; SILVA, W.R. da. Efeitos da utilização da mesa gravitacional na qualidade de sementes do feijoeiro. Pesquisa Agropecuária Brasileira, Brasília, v.19, n.12, p.1483-96, 1984.

MAGUIRE, J.D. Speed of germination-aid in selection and evaluation for seedling emergence and vigor. Crop Science, Madison, v.2, n.2, p.176-7, 1962.
MARCOS FILHO, J. Teste de envelhecimento acelerado. In: KRZYZANOVSKI, F.C.; VIEIRA, R.D.; FRANÇA NETO, J.B. Vigor de sementes: conceitos e testes. Londrina: ABRATES, 1999. cap. 3, p.1-24.

MARTINS, C.C.; NAKAGAWA, J.; BOVI, M.L.A.; STANGUERLIM, H. Influência do peso das sementes de palmito-vermelho (Euterpe espirosantensis Fernandes) na porcentagem e na velocidade de germinação. Revista Brasileira de Sementes, Brasília, v.22, n.1, p.47-53, 2000.

MENDES, A.J.T.; BACCHI, O. Os grãos mocas de café. Revista do Instituto do Café, v.XXVII, n.161, p.996-99, 1940.

MISCHAN, M.M.;PINHO, S.Z. de. Experimentação agronômica: dados não balanceados. Botucatu: FUNDIBIO, 1996. 456p.

NAKAGAWA, J. Testes de vigor baseados na avaliação das plântulas. In: VIEIRA, R.D., CARVALHO, N.M. (Ed.). Testes de vigor em sementes. Jaboticabal: FUNEP, 1994. p.49-85.

NAKAGAWA, J. Testes de vigor baseados no desempenho das plântulas. In: KRZYZANOVSKI, F.C., VIEIRA, R.D., FRANÇA NETO, J.B. (Org.). Vigor de sementes: conceitos e testes. Londrina: ABRATES, 1999. cap. 2, p.1-24.

OSORIO, B.J.; CASTILLO, Z.J. Influencia del tamaño de la semilla en el crecimiento de las plántulas de café. Cenicafé, Chinchiná, v.20, n.1, p.20-40, 1969.

POLLOCK, B.M.; ROOS, E.E. Seed and seedling vigor. In: KOZLOWSKI, T.T. (Ed.). Seed biology. New York: Academic Press, 1972. v.1, p.313-87.

POPINIGIS, F. Fisiologia da semente. 2.ed. Brasília: (s.n.), 1985. 289p.

SÃO PAULO. Secretaria de Agricultura e Abastecimento. Normas e padrões para produção de sementes e mudas de café no Estado de São Paulo. Campinas: CESM/Subcomissão técnica de café, 1997. 30p.

SIERRA, G.F.; FERNANDEZ, Q.F.; ROA, M.G.; ARCILA, P.J. Evaluación de la pérdida de calidad de la semilla de café durante su beneficio. Cenicafé, Chinchiná, v.41, n.3, p.69-79, 1990.

SILVA, R.F. da. Extração de sementes de frutos carnosos. In: CARVALHO, N.M.; NAKAGAWA, J. (Eds.). Sementes: ciência, tecnologia e produção. 4 ed. Jaboticabal: FUNEP, 2000. p.458-84.

VAUGHAN, C.E.; GREGG, B.R.; DELOUCHE, J.C. Beneficiamento e manuseio de sementes. Brasília: Ministério da Agricultura/ AGIPLAN, 1976. 195p.

VIEIRA, A.R.; OLIVEIRA, J.A.; VIEIRA, M. das G.G.C.; REIS, M. de S. Avaliação da eficiência de máquinas utilizadas no beneficiamento de sementes de arroz (Oryza sativa L.). Revista Brasileira de Sementes, Brasília, v.17, n.2, p.187-92, 1995.

YOSHIDA, R.S.; PEDROSO, P.A.C.; MALHEIROS, E.B.;SADER, R. Efeito do tamanho da semente de café (Coffea $\mathrm{sp}$ ) na germinação e vigor. Informativo ABRATES, Londrina, v.3, n.3, 1999. p.155. 